\title{
Hemispheric differences for semantically and phonologically primed nouns: A tachistoscopic study in normals
}

\author{
MANFRED RODEL and JOHN G. DUDLEY \\ University of Montreal, Montreal, Quebec, Canada \\ and \\ MARC BOURDEAU \\ Ecole Polytechnique, Montreal, Quebec, Canada
}

\begin{abstract}
Normal individuals performed two matching tasks. In one task, semantic processing, synonyms had to be recognized. Half the stimuli were picturable and half were nonpicturable nouns. In this task, recognition of picturable synonyms was found to have hemifield symmetry, whereas recognition of nonpicturable synonyms yielded a left-hemisphere superiority, indicating that semantic matching itself did not reveal equal performance of both hemispheres. It is concluded that picturable synonyms might be recognized either by processes of visual imagery, which pertain to right-hemisphere function, or by their phonological or phonic features, which are processed by the left hemisphere. The other task, shown in previous research to exhibit a left-hemisphere superiority, was to decide if two nouns (homophones) were equally pronounced. Here a distinct left-hemisphere advantage was revealed.
\end{abstract}

Words tachistoscopically presented in the right visual half-field (RVF) are generally easier to recognize than those presented in the left visual half-field (LVF) (Barton, Goodglass, \& Shai, 1965; Goodglass \& Barton, 1963; Heron, 1957; Mishkin \& Forgays, 1952). Kimura (1961) suggested that RVF advantages in word recognition were a consequence of the direct contralateral connections with the language center in the left hemisphere (LH).

Most studies have compared laterality effects for single-word recognition as a function of such lexical properties as word length, letter position, frequency of occurrence, concreteness, imageability, or syntactic class (see Searleman, 1977). Several studies have indicated that abstract and low-imageability words show a larger RVF superiority than do concrete or high-imageability words. Ellis and Shepherd (1974) presented 20 abstract and 20 concrete words to normal subjects. Concrete words yielded an insignificant LH advantage and abstract words a significant one. Hines (1976) carried out a similar experiment and observed an interaction between hemispheres and concreteness. The LH superiority was greater for

This study was supported in part by research grants from the Holderbank-Stiftung, Switzerland, and from the Stiftung für Medizinisch-Biologische Forschung, Switzerland, and in part by a grant from the Centre en Science neurologique of the University of Montreal, Canada. Requests for reprints should be addressed to Manfred Rodel, Neurological Department, University Hospital of Zürich, Raemistrasse 100, CH-8091 Zürich, Switzerland. abstract words than for concrete words. Marcel and Patterson (1979) provided evidence of a selective disability of the right hemisphere (RH) in dealing with low-imageability words. Yet, conflicting results were found by Hatta (1977) and by Saffran, Bogyo, Schwartz, and Marin (1980), who refuted these tendencies for concrete and abstract kanji characters. Nevertheless, the findings that pointed to an equal recognition of concrete and high-imageability words in left and right hemifields showed that high-frequency, concrete, picturable nouns are more likely to be successfully analyzed by the RH.

The present study assumed that hemispheric differences would be reduced or even reversed by picturable nouns, since they might be processed by a visual gestalt rather than a phonological analysis. Concrete, picturable nouns are defined as referring to objects that have a definite visual configuration and that presumably elicit very similar visual images in any French speaker who hears the names (e.g., bateau /boat/, maison /house/, valise /suitcase/). Abstract, nonpicturable nouns, however, cannot be assumed to elicit similar visual images in the minds of most French speakers. These words have been learned by being heard in context repeatedly (e.g., peine /sorrow/, rage /rage/, songe /dream/).

Several studies (Bradshaw, Bradley, Gates, \& Patterson, 1977; Bradshaw \& Gates, 1978; Day, 1977; Hirst, 1982) have shown sex differences in lateralized tachistoscopic perception. They have assumed that the female brain was less lateralized for language 
functions than the male brain. Due to the issues involved in hemispheric specialization research and sex of subject, the factor of sex will be considered in the statistical analysis of the present study.

Studies relating to hemispheric specialization for specific linguistic processes in normal individuals have provided evidence that the $\mathrm{RH}$ does possess some abilities for specific linguistic skills. However, if it is assumed that the RH is able to handle verbal input, what kind of linguistic processes are more likely to be handled by the RH? Marcel and Patterson (1979) reported that semantic priming was equally beneficial to both visual fields of presentation. Similarly, in an auditory laterality study, Eling, Marshall, and van Galen (1981) observed an overall right-ear advantage in a dichotic listening task of rhyme and semantic category monitoring, but the size of the effect was larger for rhyme than for meaning judgment. Geffen, Bradshaw, and Nettleton (1972) showed that in normal individuals the conversion of a phonological from an orthographic representation is performed more quickly or more accurately when the stimulus is presented to the RVF than when it is presented to the LVF. Such findings can be interpreted to mean that the RH can perform phonological tasks, but is merely slower and less accurate than the LH due to inhibitory effects in the LH. Another interpretation is that the RH is not able to perform such a phonological task. In Moscovitch's (1976) experiment, the task was to decide whether or not a printed letter rhymed with a previously presented spoken letter. He argued that since there were no differences between the responding hands (left or right) when stimuli were presented to the left hemifield, the RH did not demonstrate an ability to process phonological material.

In a lexical decision task, when nonwords were phonologically identical to English words, the "no" response was slower than when they were not identical (Patterson \& Marcel, 1977; Rubinstein, Lewis, \& Rubinstein, 1971). Cohen and Freeman (1979) found slower "no" responses in such a task when they presented nonwords to the RVF. The fact that a phonological interference affects only the $\mathrm{LH}$ suggests again that the $\mathrm{RH}$ does not perform phonological recoding of printed stimuli.

An alternative source for the evidence of linguistic abilities in the RH is the observation of patients recovering from aphasia produced by LH damage. In these patients, linguistic behavior might be produced by previously inoperative $R H$ mechanisms possibly inhibited by the LH. Several findings point towards this possibility. Kinsbourne (1971), using intracarotid sodium amytal, obtained direct evidence that the limited speech of some aphasic patients was originating from the RH, even though their aphasia was originally caused by LH damage. Moore and Weidner (1974) found a RVF advantage in tachistoscopic word recognition with a group of normal individuals but a LVF preference with aphasics. Lesser's (1974) findings with brain-damaged patients indicated that processing of semantic aspects of language can, unlike the processing of syntax or phonology, be impaired by damage to either hemisphere in patients with the usual LH lateralization for speech.

Considering the implications of data obtained from commissurotomized patients, the disconnected RH is capable of displaying some linguistic skills. There is evidence that the RH possesses a remarkable ability to comprehend both spoken and written common object nouns (Gazzaniga, 1970; Gazzaniga \& Hillyard, 1971) and to some degree adjectives (Gazzaniga, 1970) and even verbs (Zaidel, 1976). Levy and Trevarthen (1977) compared the performance of the disconnected hemispheres of four patients under conditions of bilateral tachistoscopic viewing. They found that the RH was dominant for visual matching of word pairs and the LH was superior at phonetic matching, but both hemispheres were able to match written words to semantic picture associates. Zaidel's (1978) results suggest that the RH is incapable of evoking a sound image to a written word and, instead, recognizes written words as visual gestalts. He showed that the split-brain RH can match pictures by rhyme and match words to pictures by meaning, but functions at a chance level when matching words to pictures by rhyme, which indicates a complete inability of the $\mathrm{RH}$ to derive phonology from print. Zaidel and Peters (1981) also reported that the RH performed more poorly than the LH in matching pictures whose names rhymed. However, Levy and Trevarthen (1977) noted that most of these commissurotomized patients appear to have received their critical brain injuries at birth. The likelihood that the language lateralization of these patients would have been abnormal because of the existence of $\mathrm{LH}$ damage since birth means that one cannot safely deduce linguistic abilities of the RH from information on split-brain studies. Currently, there is some question as to whether the observed language-comprehension skills of the disconnected RH actually reflect normal RH language function. The present study with normal individuals aims to confirm results obtained from the disconnected RH and aims to add evidence which allows inferences to be drawn from the disconnection syndrome and applied to normal subjects.

Yet another source of information for this sort of evidence derives from work on hemidecorticated individuals. These studies also provided evidence for hemispheric differences in the organization of different components of language. Syntactic discriminations were made more efficiently by right hemidecorticates (Dennis \& Kohn, 1975). Dennis and Whitaker (1976) reported that right decorticates were better than left decorticates at correcting deviant 
word strings and at analyzing syntactic structure, whereas Dennis (1980) reported that there were no significant differences between left and right hemidecorticates in making semantic discriminations of single words.

In conclusion, numerous laterality studies have provided evidence that the RH does perform some specific linguistic skills. It is suggested that the LH is more likely to be brought into play when tasks involve morphophonemic and syntactic aspects of language, whereas the RH is more likely to subserve visual processing. Both hemispheres appear to be equally capable of accessing lexical properties, when semantic judgments are required. It is suspected that lexical access goes through a phonologically mediated route in the $\mathrm{LH}$ but a visually mediated route in the RH. Therefore, in the present experiments, accuracy and reaction time were tested in non-braindamaged subjects to determine whether semantic priming is equally beneficial to both visual half-fields of presentation. Conversely, phonological priming should reveal a large RVF superiority.

\section{METHOD}

\section{Subjects}

Thirty 21-34-year-old high school graduates, whose first spoken language was French, participated in these experiments. Half of the subjects were female, and half were male. All subjects were strong familial right-handers having only right-handed parents and siblings. They had normal vision and no subject wore glasses. The selected students were not familiar with tachistoscopic procedures.

\section{Stimuli}

Two sets of stimuli were prepared for a phonological and a semantic priming experiment. The items of the first experiment, with phonological priming, consisted of 16 word pairs (three- to five-letter nouns). Eight of the word pairs were homonyms selected from a dictionary of French homonyms (Bertrand, 1980) (e.g., faim /hunger/, fin /end/; champ /field/, chant /song/, etc.), and the other eight were nonhomonyms which started with the same initial letter but were pronounced differently (e.g., roue /wheel/, rose /rose/; tarte /pie/, tante /aunt/, etc.). All word pairs consisted of semantically unrelated words. In order to accustom the subject to the procedure, four additional word pairs, two homonym and two nonhomonym pairs, served as practice items.

The stimuli of the semantic priming experiment were $\mathbf{4 8}$ highfrequency nouns (Mackey, Savard, Ardouin, 1971; VikisFreibergs, 1974) with a length of four to six letters. Of the 24 nouns that served as target words, half were semantically related (synonyms) to the test words. Synonymy was checked by reference to standard dictionaries (du Chazaud, 1979; Dupuis, 1979; Rouaix, 1904). Additionally, half the synonyms were picturable (e.g., foret /forest/, bois /wood/; route /road/, chemin /street/, etc.) and half were nonpicturable nouns (e.g., rage $/ \mathrm{rage} /$, colere /anger/; futur /future/, avenir /future/, etc.). All 24 items were presented in a randomized order. As in the first experiment, two semantically related and two semantically unrelated words were given prior to the test items and served as practice items in order to accustom the subjects to this experimental condition.

The word stimuli were written with 12-point Futura Medium Letraset capital letters and organized horizontally on 35-mm slides. Barton et al. (1965) found a consistent RVF superiority for ver- tically organized Hebrew and English words and claimed that this demonstrated cerebral asymmetry independently of any possible contribution made by scanning. Kershner and Jeng (1972) reconfirmed these findings using horizontally oriented English and vertically oriented Chinese words. Nevertheless, just as the use of bisyllabic words could present problems due to altered wordrecognition processes for longer words (Shanon, 1979), vertical presentation could introduce additional artifacts due to the uniqueness of the task (Bradshaw, Nettleton, \& Taylor, 1981; Marshall, Note 1). In the present experiment, the words were, therefore, presented horizontally. Moreover, the adoption of an unnatural vertical organization is likely to militate against possible ready recognition of whole-word features acquired through long reading experience as well as possible ends-first or letter-cluster processing. Target words were centered on the slide, whereas the test words were displaced at a visual angle of 2 deg to the left or right of the center at a viewing distance of $1 \mathrm{~m}$. The stimuli subtended visual angles of $1.3 \mathrm{deg}$ (four letters) to $2 \mathrm{deg}$ (six letters). In addition, a central fixation point (a $3-\mathrm{mm}$ cross) was drawn on the screen. Two slides of each item were made, one with the test stimulus positioned to the left of center and the other with it positioned to the right.

\section{Equipment}

The stimuli were presented by two slide projectors (Kodak Carousel, Model 700) with electronic shutters (Ralph Gerbrands, Model $G 1165$ ) mounted on the lens and positioned $45 \mathrm{~cm}$ behind a rear-projection screen (Figure 1). The target words were presented with one projector, and the immediately following test words were presented with the other projector. The stimuli appeared black on a white background. The rate of presentation and exposure duration of the slides were controlled by an eightbank timer (Lafayette, Model 5201231) that was used with two millisecond timers (Lafayette, Model 50012-50013). A clock counter (Lafayette, Model 54519-A) was also started at the onset of each test stimulus and was deactivated by a voice-active relay (Lafayette, Model 1604-A).

\section{Procedure}

The subject was seated in a chair with a head- and chinrest at a fixed distance from a rear-projection screen. He or she was told repeatedly to fix his/her gaze at a central point where a word would appear, to continue looking at the central point while a second word appeared to the left or right of center, and to make a decision, depending upon the task to be performed. He/she was expected to work as rapidly as possible and to respond with a "yes" when he/she saw a homonym or synonym, depending upon the task condition. Priming stimulus words were exposed for $300 \mathrm{msec}$, test stimulus words were exposed for $100 \mathrm{msec}$. Half of the trials were presented to the left hemifield, and half were presented to the right. An interstimulus interval of $10 \mathrm{sec}$ was maintained throughout the experiment. One half of the subjects received the phonological priming task before the semantic task, and the other half received the tasks in the reverse order. The stimuli were randomized between test conditions but remained constant within a task. Correct responses, errors, and reaction times were recorded, but the subjects were not informed of the results.

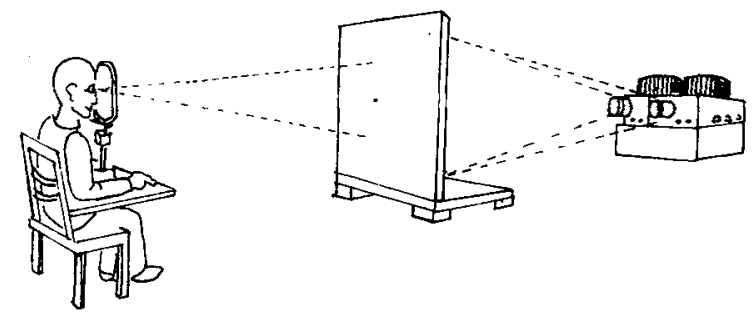

Figure 1. 


\section{RESULTS}

\section{Picturable vs. Nonpicturable Synonyms}

The number of picturable and nonpicturable synonyms in the right and left visual half-field that were recognized correctly, according to the priming stimulus, and the reaction time for these scores constituted the raw data. As indicated in the introduction to the present paper, a number of different authors have demonstrated a RVF superiority for recognition of single words, whereas other researchers have found a decrease of superiority of the RVF employing picturable or concrete nouns. These findings may be related to an increased performance of the LVF for this kind of word. Table 1 summarizes the mean accuracy scores and reaction times of picturable and nonpicturable synonyms for right and left visual half-fields.

In order to test for differences between these means, a three-way (sex $\times$ stimulus $\times$ VF) analysis of variance with repeated measures was carried out on the number of correct responses as well as on the reaction times for these responses. No significant main effect for sex and no significant interaction with sex were obtained, indicating that female and male subjects' performances were statistically equivalent. Therefore, their scores were combined for the remaining analyses. A 2 (stimuli: picturable vs. nonpicturable synonyms) $\times 2$ (visual fields) analysis of variance with repeated measures was performed. The analysis of variance for accuracy scores yielded a significant main effect for stimuli $[F(1,116)=12.47$, $p<.001]$ and for visual half-fields $[F(1,116)=22.49$, $\mathrm{p}<.001$ ] and a significant stimuli $x$ visual halffields interaction $[F(1,116)=8.56, p<.005]$.

The overall mean accuracy score of 4.15 for picturable synonyms is significantly different from the mean of $\mathbf{3 . 5 7}$ for nonpicturable synonyms. Also, the overall mean accuracy score of 8.50 for the RVF is significantly higher than the mean of 6.93 for the LVF, as demonstrated by the analysis of variance. More crucially, the significant stimuli $\times$ visual fields interaction indicated important differences between performances for the visual half-fields of picturable and rionpicturable words.
In order to analyze the significant interaction of stimuli $x$ visual fields, a posteriori mean comparisons of the picturable and nonpicturable mean accuracy scores for right and left visual half-fields were performed. The Newman-Keuls procedure (Winer, 1971) was applied to test these differences. As shown in Table 2, nonpicturable synonyms were significantly more poorly recognized in the LVF than were picturable synonyms. Both nonpicturable and picturable synonyms were significantly better recognized in the RVF than were nonpicturable synonyms in the LVF. However, there was no significant difference found between the hemifields for recognition of picturable synonyms. Picturable and nonpicturable synonyms were equally well recognized in the RVF.

The results of the analysis of variance for reaction times yielded a significant main effect for stimuli $[\mathrm{F}(1,116)=8.02, \mathrm{p}<.006]$ and an insignificant one for visual fields. The stimuli $\times$ visual fields interaction reached the statistical level of significance $[F(1,116)=4.02, p<.05]$.

The overall mean reaction time of $1,127 \mathrm{msec}$ for picturable synonyms was significantly different from the mean of $1,308 \mathrm{msec}$ for nonpicturable synonyms. However, the overall mean reaction time of $1,223 \mathrm{msec}$ for LVF is not significantly slower than the mean of $1,182 \mathrm{msec}$ for RVF. The interaction between RVF and LVF on the picturability condition was not significant, but was in the direction of supporting the hypothesis that the RH processes picturable stimuli.

As shown in Table 2, a posteriori mean comparisons of reaction times indicated that the LVF recognized nonpicturable synonyms more slowly $(p<.01)$ than picturable synonyms. Also, the LVF was slower than the RVF on both picturability conditions ( $p<$ $.05)$.

Errors were defined as responses that were not synonyms. In the tested population, the number of errors was small. Nevertheless, the mean of 2.2 for the LVF differed significantly from the mean of 1.4 for the RVF. There were no significant differences in reaction time for these false responses.

This finding provided evidence that the RH is capable of and is involved in the recognition of words

Table 1

Mean (M) and Standard Deviation (SD) of Accuracy Scores and Reaction Times (in Milliseconds) for Tachistoscopic Perception of Semantically Primed Picturable and Nonpicturable Nouns (Synonyms) and Phonologically Primed Nouns (Homonyms)

\begin{tabular}{|c|c|c|c|c|c|c|c|c|}
\hline \multirow[b]{4}{*}{ Stimuli } & \multicolumn{8}{|c|}{ Visual Fields } \\
\hline & \multicolumn{4}{|c|}{ Accuracy Scores } & \multicolumn{4}{|c|}{ Reaction Times } \\
\hline & \multicolumn{2}{|c|}{ LVF } & \multicolumn{2}{|c|}{ RVF } & \multicolumn{2}{|c|}{ LVF } & \multicolumn{2}{|c|}{ RVF } \\
\hline & $\mathbf{M}$ & SD & $\mathbf{M}$ & SD & $\mathbf{M}$ & SD & $\mathbf{M}$ & SD \\
\hline Picturable Synonyms & 4.00 & 0.74 & 4.30 & 1.06 & 1,096 & 356 & 1,158 & 312 \\
\hline Nonpicturable Synonyms & 2.93 & 0.91 & 4.20 & 0.89 & 1,405 & 429 & 1,211 & 282 \\
\hline Homonyms* & 4.53 & 0.73 & 5.25 & 0.72 & 1,156 & 396 & 941 & 253 \\
\hline
\end{tabular}

Note-LVF $=$ left visual half-field; $R V F=$ right $\mathrm{v}$ isual half-field.

*Normalized dato for accuracy scores. 
Table 2

\begin{tabular}{|c|c|c|c|c|c|c|c|}
\hline \multicolumn{8}{|c|}{$\begin{array}{l}\text { Absolute Differences Between Mean Accuracy Scores and Mean Reaction Time of RVF and LVF } \\
\text { for Picturable and Nonpicturable Synonyms and Critical Differences Required } \\
\text { for Significance According to the Newman-Keuls Procedure }\end{array}$} \\
\hline & & \multicolumn{4}{|c|}{ Accuracy Scores } & & \\
\hline & & $\begin{array}{c}\text { Nonpic } \\
\text { Synonyms }\end{array}$ & $\begin{array}{c}\text { Pic } \\
\text { Synonyms }\end{array}$ & $\begin{array}{c}\text { Nonpic } \\
\text { Synonyms }\end{array}$ & $\begin{array}{c}\text { Pic } \\
\text { Synonyms }\end{array}$ & & \\
\hline & & LVF & LVF & RVF & RVF & \multicolumn{2}{|c|}{$1-\alpha$} \\
\hline & & 2.93 & 4.00 & 4.20 & 4.30 & $95 \%$ & $99 \%$ \\
\hline & & & $1.07 * *$ & $\begin{array}{l}1.27^{* *} \\
.20\end{array}$ & $\begin{array}{l}1.37 * * \\
.30 \\
.10\end{array}$ & $\begin{array}{l}.86 \\
.79 \\
.66\end{array}$ & $\begin{array}{r}1.05 \\
.98 \\
.87\end{array}$ \\
\hline $\begin{array}{l}285.5 \\
266.5 \\
234.8\end{array}$ & $\begin{array}{l}177.7 \\
213.2 \\
234.1\end{array}$ & $\begin{array}{l}194^{*} \\
247^{*} \\
309^{* *}\end{array}$ & $\begin{array}{r}53 \\
115\end{array}$ & 62 & & & \\
\hline $99 \%$ & $95 \%$ & 1,405 & 1,211 & 1,158 & 1,096 & & \\
\hline \multicolumn{2}{|c|}{$1-a$} & LVF & RVF & RVF & LVF & & \\
\hline & & $\begin{array}{c}\text { Nonpic } \\
\text { Synonyms }\end{array}$ & $\begin{array}{c}\text { Nonpic } \\
\text { Synonyms }\end{array}$ & $\begin{array}{c}\text { Pic } \\
\text { Synonyms }\end{array}$ & $\begin{array}{c}\text { Pic } \\
\text { Synonyms }\end{array}$ & & \\
\hline & & \multicolumn{4}{|c|}{$\begin{array}{l}\text { Reaction Time } \\
\text { (in Milliseconds) }\end{array}$} & & \\
\hline
\end{tabular}

that are picturable and can be recognized by means of a visually mediated route.

\section{Semantic vs. Phonological Parameter}

Another question is addressed to the righthemisphere engagement in specific linguistic skills. Recent studies have indicated that the RH has a semantic access to the lexicon, although most of these investigations used subjects with brain disorders. In order to demonstrate differential involvement between the hemispheres, the semantic task was paired with a phonological task. Table 1 presents the mean accuracy scores and the mean reaction times for the phonological task presented to both visual half-fields.

A LH superiority for the recognition of phonologically primed words was postulated. First, a onetailed $t$ test was carried out to verify this hypothesis. In the phonological task, the accuracy scores of the RVF were significantly better than those of the LVF $[F(1,58)=14.83, p<.005]$ as was reaction time $[F(1,58)=6.33, p<.04]$. The same results were obtained for the error scores.

Due to the striking hemifield differences for picturable and nonpicturable synonyms, the results of the phonologically primed task were compared with the results of the semantically primed picturable synonyms and of the semantically primed nonpicturable synonyms. In order to compare the results of the phonological and the semantic priming tasks, the data were adjusted to equalize the number of stimuli between the two task conditions. A three-way (sex $\times$ experimental condition $\times V F$ ) analysis of variance with repeated measures was performed. Neither the main effect of sex nor any interaction with sex approached significance, confirming that female and male subjects performed equally well on both tasks. Scores were, therefore, collapsed across the sex variable for the remaining analyses. A two-way analysis of variance with repeated measures (experimental condition: phonologically vs. semantically primed picturable/nonpicturable synonyms $\times$ visual fields) was carried out on both the accuracy scores and the reaction times for these responses.

In the first analysis, semantically primed nonpicturable synonyms were compared with homonyms. The results yielded significant main effects on accuracy scores for experimental conditions $[F(1,116)=$ $75.32, \mathrm{p}<.001]$ and for visual fields $[F(1,116)=$ 44.48, $\mathrm{p}<.001]$. The interaction effect did not reach statistical significance.

The overall mean score of 4.89 for homonyms was significantly better than that of 3.57 for nonpicturable synonyms. The mean of 4.73 for the RVF was significantly higher than that of 3.73 for the LVF, as demonstrated by the analysis of variance.

The a posteriori mean comparisons in Table 3 demonstrated a nonsignificant experimental conditions $\times$ visual fields interaction. This finding indicates a RVF superiority for the recognition of both homonyms and nonpicturable synonyms. Fewer nonpicturable synonyms than homonyms were recognized by either visual field. Recognition of nonpicturable synonyms in the RVF was almost equal to that of homonyms in the LVF.

With regard to reaction time, significant main effects were obtained for experimental conditions 
Table 3

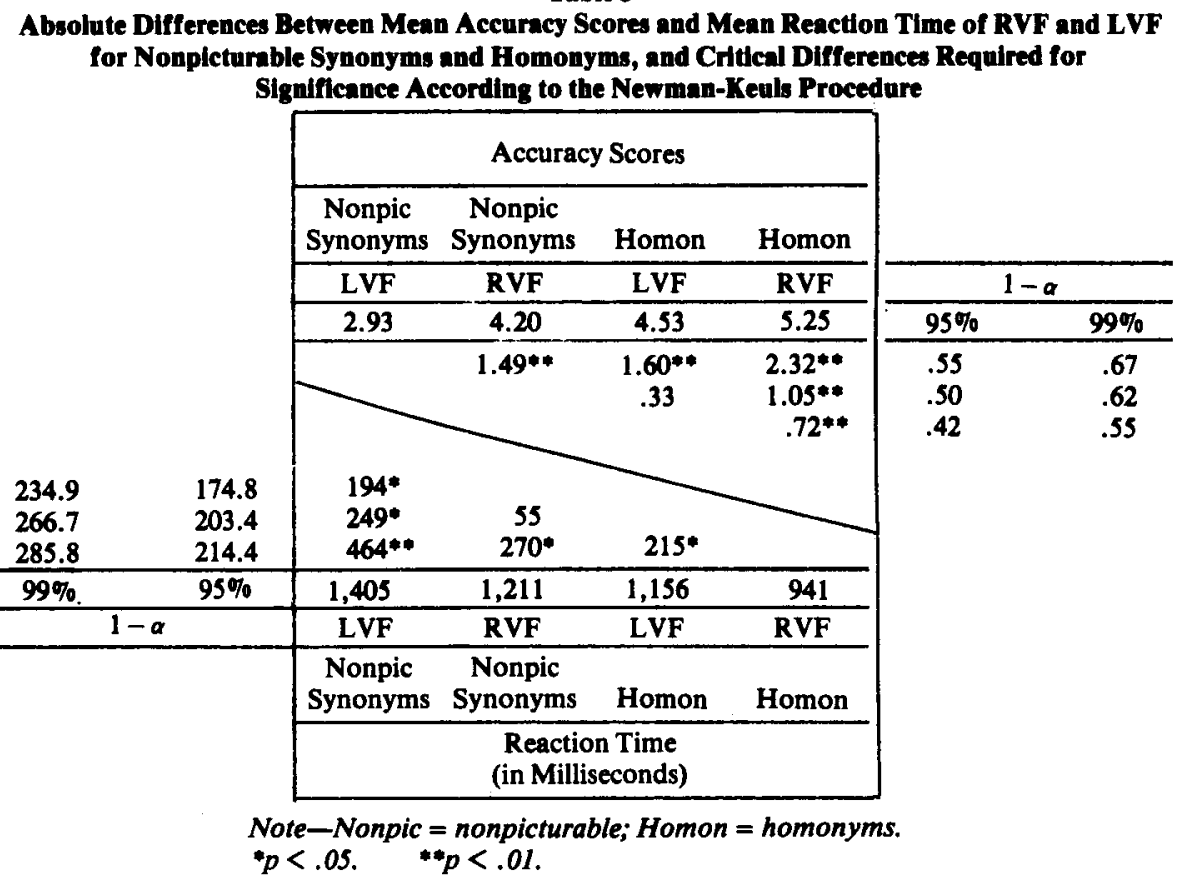

$[F(1,116)=16.62, p<.001]$ and for visual fields $[F(1,116)=10.39, \mathrm{p}<.002]$ but not for their interaction.

The overall mean reaction time of $1,308 \mathrm{msec}$ for recognition of nonpicturable synonyms was significantly slower than that of $1,049 \mathrm{msec}$ for recognition of homonyms. As shown by a posteriori mean comparisons, nonpicturable synonyms took significantly longer to recognize than homophones in both hemifields. The mean comparisons also indicated that the RVF was significantly superior to the LVF for both homonyms and nonpicturable synonyms. The mean reaction time for nonpicturable synonyms in the RVF was insignificantly slower than that for recognition of homophones in the LVF.

In a second analysis, accuracy scores and reaction time for recognition of picturable synonyms were compared with those of homonyms. Based on the accuracy scores, the analysis of variance yielded significant main effects for experimental conditions $[F(1,116)=22.30, p<.001]$ and for visual fields $[F(1,116)=11.54, p<.001]$, but not for their interaction.

A posteriori mean comparisons indicated that recognition of homonyms by the RVF was significantly better than it was by the LVF and also significantly better than the recognition of picturable synonyms by either hemifield. The significant visual field effect for homonyms was produced by a difference between hemifields in favor of the RVF, whereas no significant hemifield difference was found for recognition of picturable synonyms.
Analysis of the reaction times produced no significant main effect, but the interaction was significant $[F(1,116)=5.20, p<.05]$. This effect is a result of the fact that there were nearly equal reaction times for picturable synonyms and homonyms in the LVF, whereas the synonyms required more time to recognize in the RVF.

\section{DISCUSSION AND CONCLUSION}

Findings elsewhere of an interaction between hemifield advantages and sex deserve to be noted. Day (1977) mentioned that six of his subjects showed a left-hemifield advantage for abstract nouns, and five of these subjects were female. Other investigators (Bradshaw et al., 1977; Bradshaw \& Gates, 1978) have demonstrated reduced right-hemifield advantages for females in a lexical decision task. It has been hypothesized that the female brain is more functionally symmetrical for language than is the male brain, and a female superiority in verbal abilities was, therefore, alleged, but it is not yet clear whether the female superiority is innate (Hirst, 1982). In the present study, however, the performance of female and male subjects, who differed in neither age nor educational background, was equal.

We had assumed that picturable nouns, which possess a visual configuration which all subjects can perceive, were equally well recognized by either hemisphere. Processes of visual imagery might be mediated by the $\mathrm{RH}$, while phonological decoding might be processed by the LH. This assumption was mainly 
Table 4

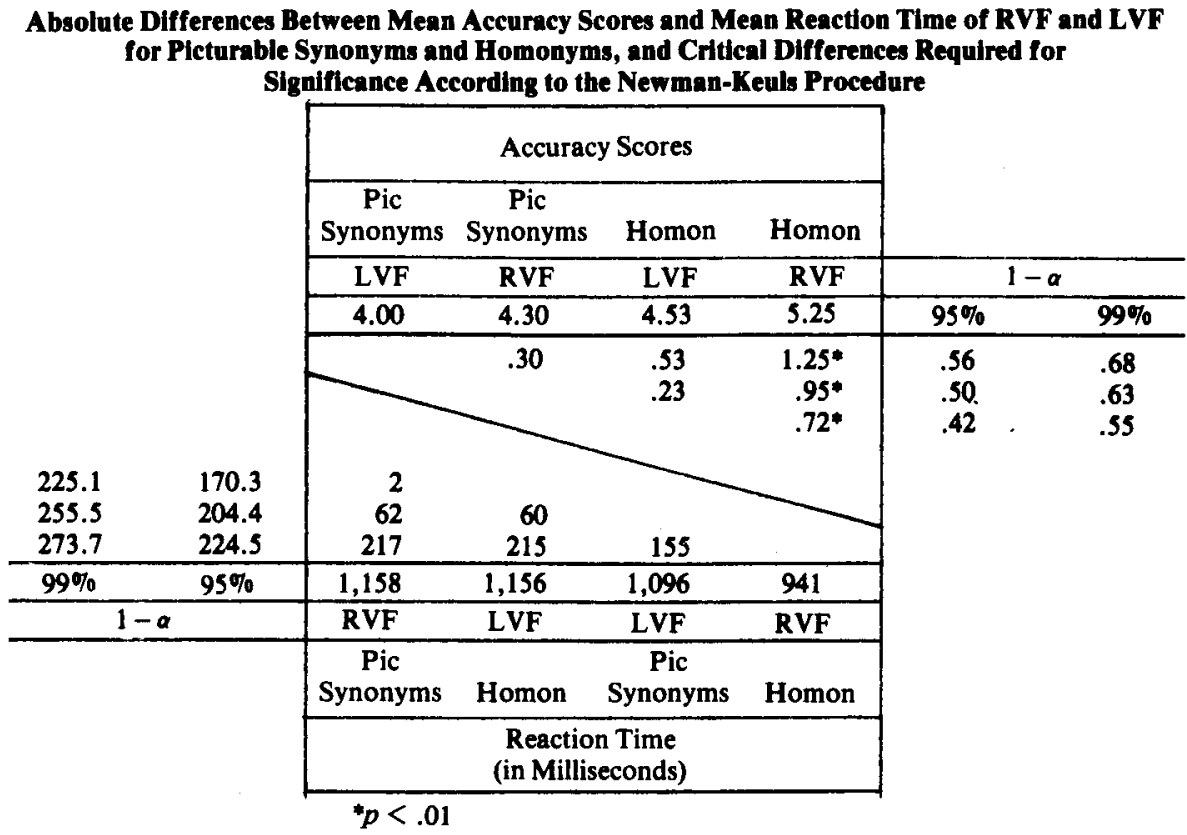

confirmed, since striking evidence of hemispheric symmetry for recognition of semantically primed picturable nouns (synonyms) was observed, whereas a LH superiority for such nonpicturable nouns was found. The present results are in accordance with previous findings with reference to concreteness and imageability (Day, 1977, 1979; Ellis \& Shepherd, 1974; Hines, 1976, 1977). These authors indicated an interaction between hemispheres and concreteness/ imageability in such a manner that both hemispheres showed statistically equal performance in recognition of concrete, and hence imaginable, words. Marcel and Patterson (1979) also reported that, with RH presentation, low-imageability words were much less accurately recognized than high-imageability words.

According to the literature on deep dyslexia, the RH displays semantic representations of language (Coltheart, Patterson, \& Marshall, 1980; Marshall \& Newcombe, 1966; Saffran \& Marin, 1977; Saffran, Schwartz, \& Marin, 1976). Contrary to expectation, equal performance of the two visual half-fields was not obtained for all semantic matchings, but was for the matching of picturable synonyms. It should be pointed out that the semantic and the phonological matching tasks differed in their functional processing requirements. In the semantic task, subjects had first to generate the meaning through an imagery process or phonological decoding or holographic processes (Pribram, 1971), and then to match the meaning, whereas in the phonological task only a matching process was required. The greater difficulty of the semantic task might thus have impaired accuracy as well as increased response latencies, as compared with the phonological task, and possibly may have done so to such an extent that a presumed RH in- volvement might have been obscured for semantic judgments of nonpicturable synonyms. The results obtained pointed to the fact that semantic judgments of picturable and nonpicturable synonyms were processed differently, and the differing extent of lateralization for picturable and nonpicturable synonyms led to the view that semantic processing itself might not necessarily be performed by the RH. This interpretation is in accordance with the findings of previous studies. In those studies, a LH superiority for semantic category judgments was found, although it was not very stable (Day, 1977; Gross, 1972; Urcuioli, Klein, \& Day, 1981). Eling, Marshall, and van Gelen (1981) and Martin (1978) reported a less pronounced LH superiority for semantic category judgments than for nonsemantic judgments, suggesting that there is yet some RH involvement in semantic category matching.

The converse findings by Dennis (1980), who reported no significant difference between left and right hemidecorticates in making semantic discriminations of single words, could be explained by a difference in the functioning of the decorticated $\mathrm{RH}$, which is no longer under the inhibiting influence of the $\mathrm{LH}$.

Different strategies may be employed to distinguish two semantically related words, and these strategies may involve the $\mathrm{LH}$ or the $\mathrm{RH}$, or both. Two words can be matched by their visible patterns, by their orthographic representation, or by letter-byletter, cluster-by-cluster, or even global analysis. Gibson, Dimond, and Gazzaniga (1972) and Levy and Trevarthen (1977) found a RH dominance for the matching of words by visual identity as a result of the ability of the RH to retain in memory the crit- 
ical relations in the form of visual displays. However, some subjects may have arrived at their decisions on the basis of whether the words both sounded and looked alike. In such a case, a LVF superiority would be obscured, since there might be some $\mathrm{LH}$ involvement in phonologically matching the words (Levy \& Trevarthen, 1977). In the present study, two different words had to be matched according to semantic or phonological similarity. Thus, words had to be analyzed by their semantic or their phonological features. In the phonological matching task, the association was based upon similar sound patterns and not necessarily upon similar visual features. Therefore, words had to be matched by their sound patterns and not by their visible patterns. The LH superiority for this task pointed to RH's lack of a phonetic analyzer that generates phonetic images. These findings, obtained from normal subjects, are in accordance with those of Zaidel (1978), who reported a complete inability of the disconnected RH to derive phonology from print.

More crucial were the findings of the semantic judgment task, which indicated that picturable and nonpicturable synonyms might be processed through different pathways. The lexicon might be assessed by the orthographic representation of a word or by its phonological features. But it is also conceivable that picturable words are recognized by gestalt laws of figural organization which reflect processes of visual imagery. Furthermore, words whose lexical access does not occur by means of orthographic or phonological pathway or gestalt features may even be stored on a more complex cognitive level.

The results of this research lead us to conclude that the LH is superior for analyzing phonological patterns, indicating that it might possess a phonetic encoder that is competent not only for the control of speech, but also for the recognition of phonic similarities, while visual imagery is mainly a RH function in man. These findings add to the growing evidence that there are hemispheric symmetries for picturable synonyms which share mutual visual configurations and which are available to all subjects to the same extent. However, nonpicturable synonyms may be matched by means of their phonological or phonic representation.

\section{REFERENCE NOTE}

1. Marshall, J. Personal communication, 1982.

\section{REFERENCES}

Barton, M. I., Goodglass, H., \& Shai, A. Differential recognition of tachistoscopically presented English and Hebrew words in right and left visual fields. Perceptual and Motor Skills, 1965, 21, 431-437.

Bertrand, J. Dictionnaire pratique des homonymes. Paris: Collection Pluriguides Nathan, 1980.

Bradshaw, J. L., Bradley, D., Gates, A., \& Patterson, K.
Serial, parallel or holistic identification of single words in the two visual fields? Perception \& Psychophysics, 1977, 21, 431-438.

Bradshaw, J. L., \& Gates, A. Visual field differences in verbal tasks: Effects of task familiarity and sex of subject. Brain and Language, 1978, 5, 166-187.

Bradshaw, J. L., NetTleton, N. C., \& Taylor, M. J. The use of laterally presented words in research into cerebral asymmetry: Is directional scanning likely to be a source of artifact? Brain and Language, 1981, 14, 1-14.

Conen, G., \& Freeman, R. Individual differences in reading strategies in relation to handedness and cerebral asymmetry. In J. Requin (Ed.), Attention and performance VII. Hillsdale, N.J: Erlbaum, 1979.

Coltheart, M., Patterson, K., \& Marshall, J. C. (EDs.). Deep dyslexia. London: Routledge and Kegan Paul, 1980.

DAY, J. Right-hemisphere language processing in normal righthanders. Journal of Experimental Psychology: Human Perception and Performance, 1977, 3, 518-528.

DAY, J. Visual half field word recognition as a function of syntactic class and imageability. Neuropsychologia, 1979, 17, 517-519.

Dennis, M. Language acquisition in a single hemisphere: Semantic organization. In D. Caplan (Ed.), Biological studies of mental processes. Cambridge, Mass: M.I.T. Press, 1980.

Dennis, M., \& KoHs, B. Comprehension of syntax in infantile hemiplegics after cerebral hemidecortication: Left hemisphere superiority. Brain and Language, 1975, 2, 472-482.

Dennis, M., \& Whitaker, H. A. Language acquisition following hemidecortication: Linguistic superiority of the left over the right hemisphere. Brain and Language, 1976, 3, 404-433.

Du Chazaud, H. B. Dictionnaire des synonymes. Paris: Le Robert, 1979.

Dupu1s, H. Dictionnaire des synonymes et des antonymes. Montréal: Editions Fides, 1979.

Eling, P., Marshall, J., \& van Galen, G. The development of language lateralization as measured by dichotic listening. Neuropsychologia, 1981, 19, 767-773.

Ellis, H. D., \& She Phe RD, J. W. Recognition of abstract and concrete words presented in left and right visual fields. Journal of Experimental Psychology, 1974, 103, 1035-1036.

Gazzaniga, M. S. The bisected brain. New York: AppletonCentury-Crofts, 1970.

Gazzaniga, M. S., \& Hillyand, S. A. Language and speech capacity of the right hemisphere. Neuropsychologia, 1971, 9, 273-280.

Geffen, G., Bradshaw, J. L., \& Nettleton, N. C. Hemispheric asymmetry: Verbal and spatial encoding of visual stimuli. Journal of Experimental Psychology, 1972, 93, $25-31$.

Gibson, A., Dimond, S., \& Gazzaniga, M. S. Left field superiority for word matching. Neuropsychologia, 1972, 10, 446-463.

Goonglass, H., \& Barton, M. I. Handedness and differential perception of verbal stimuli in left and right visual fields. Perceptual and Motor Skills, 1963, 17, 851-854.

Gross, M. M. Hemispheric specialization for processing of visually presented verbal and spatial information. Perception \& Psychophysics, 1972, 12, 357-363.

HatTA, T. Lateral recognition of abstract and concrete kanji in Japanese. Perceptual and Motor Skills, 1977, 45, 731-734.

Heron, W. Perception as a function of retinal locus and attention. American Journal of Psychology, 1957, 70, 38-48.

Hines, D. Recognition of verbs, abstract nouns and concrete nouns from the left and right visual half-fields. Neuropsychologia, 1976, 14, 211-216.

Hines, D. Differences in tachistoscopic recognition between abstract and concrete words as a function of visual half-field and frequency. Cortex, 1977, 13, 66-73.

H!rst, G. An evaluation of evidence for innate sex differences in linguistic ability. Journal of Psycholinguistic Research, 1982, 11, 95-113.

Kershner, J. R., \& JenG, A. G. R. Dual functional hemispheric asymmetry in visual perception: Effects of ocular dominance 
and post exposural processes. Neuropsychologia, 1972, 10 , 437-445.

Kimura, D. Some effects of temporal lobe damage on auditory perception. Canadian Journal of Psychology, 1961, 15, 156-165.

KinsBourne, M. The minor cerebral hemisphere as a source of aphasic speech. Archives of Neurology, 1971, 25, 302-306.

Lesser, R. Verbal comprehension in aphasia: An English version of three Italian tests. Cortex, 1974, 10, 247-263.

Levy, J., \& Trevarthen, C. Perceptual, semantic and phonetic aspects of elementary language processes in split-field patients. Brain, 1977, 100, 105-108.

Mackey, W. F., Savard, J.-G., \& Ardouin, P. Le vocabulaire disponible du français. Tome I \& II. Montréal: Marcel Didier (Canada) Ltée., 1971.

Marcel, A. J., \& Patterson, K. Word recognition and production in clinical and normal research. In J. Requin (Ed.), Attention and performance VII. Hillsdale, N.J: Erlbaum, 1979.

Marshall, J. C., \& Newcombe, F. Syntactic and semantic errors in paralexia. Neuropsychologia, 1966, 4, 169-176.

Martin, M. Hemispheric asymmetries for physical and semantic selection of visually presented words. Neuropsychologia, 1978, 16, 717-724.

Mishrin, M., \& Forgays, D. G. Word recognition as a function of retinal focus. Journal of Experimental Psychology, 1952, 43, 43-48.

Moone, W. H., \& Weidner, W. E. Bilateral tachistoscopic word perception in aphasic and normal subjects. Perceptual and Motor Skills, 1974, 39, 1003-1011.

Moscovitch, M. On the representation of language in the right hemisphere of right-handed people. Brain and Language, 1976, 3, 47-71.

Patterson, K., \& Marcel, A. J. Aphasia, dyslexia and the phonological coding of printed words. Quarterly Journal of Experimental Psychology, 1977, 29, 307-318.

Pribram, K. H. Languages of the brain. Englewood cliffs, N.J: Prentice-Hall, 1971.

Rounix, P. Dictionnaire-manual illustré des idées sugérées par les mots. Paris: Librairie Armand Collin, 1904.
Rubinstein, H., Lewis, S. S., \& Rubinstein, M. A. Evidence for phonemic recoding in visual word recognition. Journal of Verbal Learning and Verbal Behaviour, 1971, 10, 647-657.

Saffran, E. M., Bogyo, L. C., Schwartz, M. F., \& Marin, O. S. M. Does deep dyslexia reflect right-hemisphere reading? In M. Coltheart, K. Patterson, \& J. C. Marshall (Eds.), Deep dyslexia. London: Routledge and Kegan Paul, 1980.

Saffran, E. M., \& Marin, O. S. M. Reading without phonology: Evidence from aphasia, Quarterly Journal of Experimental Psychology, 1977, 29, 515-525.

Saffran, E. M., Schwartz, M. F., \& Marin, O. S. M. Semantic mechanisms in paralexia. Brain and Language, 1976, 3, 255-265.

Searleman, A. A review of right hemisphere linguistic capabilities. Psychological Bulletin, 1977, 84, 503-528.

Shanon, B. Lateralization effects in response to words and nonwords. Cortex, 1979, 15, 541-549.

Urcuioli, P., KLein, R., \& DAY, J. Hemispheric differences in semantic processing: Category matching is not the same as category membership. Perception \& Psychophysics, 1981, 29, 343-351.

VIKIs-Freiberas, V. Fréquence d'usage des mots au Québec. Études psycholinguistiques d'un échantillon de la région montréalaise. Montréal: Les Presses de l'Université de Montréal, 1974.

WINER, B. J. Statistical principles in experimental design. London and New York: McGraw-Hill, 1971.

ZAIDEL, E. Auditory vocabulary of the right hemisphere following brain bisection or hemidecortication. Cortex, 1976, 12, 191-211.

ZaIDes, E. Lexical organization in the right hemisphere. In $P$. Buser \& A. Rongeul-Buser (Eds.), Cerebral correlates of conscious experience. Amsterdam: Elsevier, 1978.

Zaidel, E., \& Peters, A. M. Phonological encoding and ideographic reading by the disconnected right hemisphere: Two case studies. Brain and Language, 1981, 14, 205-234.

(Manuscript received February 21, 1983; revision accepted for publication August 31,1983 .) 